\title{
Recurrence in prostate cancer: salvage diagnostic and therapeutic strategies
}

\author{
Sanchia Goonewardene ${ }^{1}$
}

Published online: 27 April 2019

○) Springer-Verlag GmbH Germany, part of Springer Nature 2019

Welcome to a special topic issue on Salvage Therapies in Prostate Cancer. On behalf of my team at WJU, it has been a pleasure to put this together for you.

Prostate cancer is an incredibly common problem, more so, salvage therapy in prostate cancer. More and more patients are diagnosed and treated, yet in later years have recurrent disease [7]. This is due to an underlying aggressive pathology [9]. The real question is what can we as clinicians do in these situations? What will help our patients more? What are the best diagnostic and treatment modalities and for which patient?

As urologists, it is important for us to diagnose recurrent disease early and treat quickly [8]. Henk Van der Poel, clearly highlights the role of MRI in his paper, as a part of the diagnostic pathway. A multicentre study was also conducted by Giancarlo Marra, examining the role of prostate biopsy in salvage cases [5]. These two papers both emphasise the re-grading and staging of recurrent prostate cancer as of paramount significance. When dealing with a case of recurrent prostate cancer, diagnostics are no different than when dealing with a primary prostate cancer, only with the addendum, it is far more aggressive disease with significant operative challenges.

Outcomes are a clear factor in what we can do differently in our surgical technique. Gabriel Ogaya-Pinies, Morgan Roupret and Rafael Sanchez-Salas highlight robotic outcomes in salvage prostatectomy [1]. Salvage prostatectomy is one of the most difficult operations in urology, due to lack of good tissue planes, yet, when in experienced hands, it gives remarkable outcomes. Experience is key in an operation where anatomical markers are often none existent.

An alternative to surgery, is focal therapy. This is examined by Steven Joniau, which is another possible treatment modality. Many would argue that focal therapy should not

Sanchia Goonewardene

ssg7727@yahoo.co.uk

1 East of England Deanery, Southend, UK be used in disease with multifocal pathology. However, this paper highlights reasonable outcomes from focal therapy. The most important factor when dealing with salvage therapy for the prostate, is to diagnose the patient quickly and then treat the patient with the most appropriate modality for them. In certain cases, this would mean focal therapy. An argument has even been made for focal therapy in the case of radiorecurrent prostate cancer [4] in the past. This is still under debate.

Despite good diagnostics, many in this group of patients often present with metastatic disease [3]. By definition recurrent prostate cancer is more aggressive disease. Simone Albisinni examined PSMA PET-directed radiotherapy for oligometastatic disease after prostatectomy, this is a possible treatment option that could be used, in the frailer patient group. This is clearly important as it allows for a targeted therapy in the case of metastatic disease [2,6]. Alternatively, for patients fit for surgery Steven Joniau examined metastectomy for visceral and skeletal oligorecurrent prostate cancer. This again highlights how far prostate cancer treatment has developed-to considering metastectomy in fit patients.

We hope this edition highlights issues and helps guide your practice in Salvage Therapy for Prostate Cancer.

Sanchia Goonewardene MBChB(Hons.Clin.Sc) BMedSc(Hons) PGCGC Dip.SSc MRCS (UK) MPhil

Specialist Registrar, East of England Deanery

World Journal of Urology Editorial Board

\section{References}

1. Clery R, Grande P, Seisen T, Gobert A, Duquesne I, Villers A, Olivier J, Bernhard JC, Robert G, Beauval JB, Prudhomme T, Bruyere F, Laine-Caroff P, Waltregny D, Guillonneau B, Panarello D, Ruffion A, de Bayser H, de la Taille A, Roupret M (2019) Outcomes after salvage radical prostatectomy and first-line radiation therapy or HIFU for recurrent localized prostate cancer: results from a multicenter study. World J Urol. https://doi.org/10.1007/ s00345-019-02683-0 
2. Goonewardene S, Alsheikh M (2018) The role of PSMA PET scans in salvage therapy planning. World J Urol 36:503-504

3. Goonewardene SS, Cahill D (2016) Is there a role for salvage lymphadenectomy as second-line therapy post-robotic radical prostatectomy? World J Urol 34:1247-1248

4. Kanthabalan A, Arya M, Punwani S, Freeman A, Haroon A, Bomanji J, Emberton M, Ahmed HU (2013) Role of focal salvage ablative therapy in localised radiorecurrent prostate cancer. World J Urol 31:1361-1368

5. Marra G, Gontero P, Walz JC, Sivaraman A, Tourinho-Barbosa R, Cathelineau X, Sanchez-Salas R (2019) Complications, oncological and functional outcomes of salvage treatment options following focal therapy for localized prostate cancer: a systematic review and a comprehensive narrative review. World J Urol. https://doi. org/10.1007/s00345-019-02642-9

6. Rauscher I, Horn T, Eiber M, Gschwend JE, Maurer T (2018) Novel technology of molecular radio-guidance for lymph node dissection in recurrent prostate cancer by PSMA-ligands. World J Urol 36:603-608
7. Rosoff JS, Savage SJ, Prasad SM (2013) Salvage radical prostatectomy as management of locally recurrent prostate cancer: outcomes and complications. World J Urol 31:1347-1352

8. Sathianathen NJ, Butaney M, Konety BR (2018) The utility of PET-based imaging for prostate cancer biochemical recurrence: a systematic review and meta-analysis. World J Urol. https://doi. org/10.1007/s00345-018-2403-7

9. Williams SB, Hu JC (2013) Salvage robotic assisted laparoscopic radical prostatectomy: indications and outcomes. World J Urol $31: 431-434$

Publisher's Note Springer Nature remains neutral with regard to jurisdictional claims in published maps and institutional affiliations. 